Theory for

Midwifery Practice 


\title{
Midwifery Practice
}

SERIES EDITORS: JO ALEXANDER, VALERIE LEVY, SARAH ROCH.

\author{
Antenatal Care \\ Intrapartum Care \\ Postnatal Care
}

Midwifery Practice: A Research-based approach.

FORTHCOMING MACMILLAN TITLES

Kargar (ed): Challenges for Midwifery Practice

Hunt \& Symonds: The Social Meaning of Midwifery 


\section{Theory for \\ Midwifery Practice}

ROSAMUND M. BRYAR

Department of Nursing and Midwifery

University of Wales Swansea 


\section{(C) Rosamund M. Bryar 1995}

All rights reserved. No reproduction, copy or transmission of this publication may be made without written permission.

No paragraph of this publication may be reproduced, copied or transmitted save with written permission or in accordance with the provisions of the Copyright, Designs and Patents Act 1988, or under the terms of any licence permitting limited copying issued by the Copyright Licensing Agency, 90 Tottenham Court Road, London W1P 9HE.

Any person who does any unauthorised act in relation to this publication may be liable to criminal prosecution and civil claims for damages.

First published 1995 by MACMILLAN PRESS LTD

Houndmills, Basingstoke, Hampshire RG21 2XS and London Companies and representatives throughout the world

ISBN 978-0-333-58867-3 ISBN 978-1-349-13151-8 (eBook)

DOI 10.1007/978-1-349-13151-8

A catalogue record for this book is available from the British Library 
For my parents, Bernard Laurence

and Mary Forbes Bryar 
List of Figures

viii

List of Tables

Preface

ix

Acknowledgements

1 Introduction 1

2 Thinking about midwifery 13

3 The context of midwifery care 44

4 Models and theories influencing midwifery care $\quad 74$

5 Current concepts of midwifery practice 104

6 Five midwifery theorists 126

7 Approaches to theory building in midwifery 165

8 Developing theory for midwifery practice 202

$\begin{array}{ll}\text { References } & 219\end{array}$

$\begin{array}{ll}\text { Index } & 237\end{array}$ 
2.1 The feedback relationship between fear, tension and pain

2.2 Disciplines underpinning preconceptual care 32

2.3 Concepts central to midwifery care 40

3.1 The action approach to organisations 56

3.2 The action framework and care of the childbearing woman $\quad 57$

4.1 The medical model: consequences for practice 81

4.2 The Health for All model: consequences for practice 90

5.1 Continuum contrasting the medical model of pregnancy and the model of pregnancy as a normal life-event

6.1 Rubin's model of attainment of the maternal role

6.2 Linear representation of Rubin's model of attainment of the maternal role

6.3 Mercer's model of the relationship between antepartum stress and family functioning

6.4 A representation of Mercer's model of adaptation to the maternal role in the first year of motherhood

6.5 Relationship of concepts of midwifery care identified by Ela-Joy Lehrman and Morten et al.

6.6 Ernestine Wiedenbach's model of nursing (midwifery) practice

6.7 Factors identified by Jean Ball as affecting emotional well-being

6.8 Support systems for maternal well-being 
2.1 The relationship between paradigms, philosophies, models, theories and concepts

5.1 Nationwide aims for Page's five year strategy for development of midwifery services

6.1 Analysis of the aspects of nurse-midwifery practice content categories

7.1 Models used for maternity care 
For me the writing of this book has been a journey, and I feel that I have come part of the way on that journey. My journey has been affected by my own questions, by the questions of others, by all the things that I have read and my knowledge and awareness of midwifery. Throughout this book the need for all midwives to clarify and try to state their beliefs and pictures of midwifery care is emphasised. Here I want to try to explain some of the questions I have had during the preparation of this book and some of the influences on my beliefs and picture of midwifery practice. My questions and concerns may be the same as yours, as you use this book in your own journey of thinking about midwifery practice, or your questions may be very different.

On the face of it I was not the ideal person to write a book such as this, about the development and use of theory or models in midwifery. I have never taught courses about the use of theory nor been greatly involved in the utilisation of models in midwifery or nursing practice except as a research midwife in the early 1980s at Queen Charlotte's Maternity Hospital. As a lecturer and external examiner I have been involved in the assessment of work using nursing models, both work in midwifery and different areas of nursing, but I have been largely an observer rather than a participant in the discussions about the use of models in midwifery or nursing. However, since my experience in the early 1980s, I had thought that there was a need for a book which considered theory development in midwifery but I had made no attempts to write such a book because of the reasons just given and because I realised the work that would be involved! In addition, my career had taken me away from midwifery back to primary health care.

When, unexpectedly, I was presented with the opportunity to prepare this book I realised that it was time someone had a go at it and, after some persuasion, I agreed. My aim has been to examine the basis of concept identification and theory development, to present information about work which has been done in this area in midwifery and to raise questions about this process. I was one of the early graduates from the Department of Nursing in Manchester, where Dr Dorothy Baker, Dr Charlotte Kratz, Emeritus Professor Baroness Jean McFarlane and Miss Norah Marsh ensured that we had the ability to go back to first principles and ask questions, and this is what I have tried to do in this book.

My first introduction to the use of theory in practice came early in my degree in Manchester in 1971 when Miss Marsh discussed with us Virginia Henderson's definition of nursing. This definition had a significant impact on me but I have little recollection of any other 
discussions of nursing theory in my degree, although we were encouraged to use the nursing process tool in recording our care. After I graduated I worked briefly in medical nursing, qualified as a midwife and worked as a health visitor. In none of these posts was there much discussion or evidence of the use of nursing/midwifery/health visiting theory in practice. It wasn't until I went to Queen Charlotte's Maternity Hospital as a research midwife in 1979 that I found myself thinking to any extent about the use of theory in practice.

The aim of the project at the hospital was to develop individualised care for childbearing women who were receiving care from the hospital. Much of the activity of the project was concentrated on changing parts of the organisation of the midwifery service to achieve continuity of care. For example, each woman was allocated to a midwife in the antenatal clinic who was then meant to see them on all subsequent clinic visits, and staff allocation rather than task allocation was introduced on the wards. In addition, care planning was introduced and this led us to consider models of care which could be utilised to underpin care planning. Due to the apparent lack of midwifery models, this consideration was of nursing models and the application of such models to midwifery. At that time little work had been done on the application of nursing models to midwifery and few midwives were familiar with nursing models. Given the extent of other changes that the project was seeking to introduce it was decided that a more pragmatic approach should be taken rather than trying to teach everyone about nursing models. In the event we held meetings with the midwives at which we tried to draw from them their model(s) of care. This process resulted in the midwifery assessment which can be seen as a very early, rather halting, attempt to crystallise some of the concepts underpinning midwifery practice. The project did not try to apply one model to midwifery care and midwives using the assessment and care plans largely applied their own personal, unstated models to the process of assessment and care planning.

Throughout this project there was a constant nagging problem. We never seemed able to discuss or question the actual care that was being given. The project was focused on changing organisational factors (but only those factors affecting midwifery practice) and introducing new recording systems but could not get near questions such as: What care was being given? What was the content of that care? What was the quality of that care? What was the thinking which lay behind that care? There was a general assumption that the care was good and that, once some organisational changes had been made, care would be individualised and continuity achieved. 
Following the end of the project I worked for a while in Gloucester Maternity Hospital where I was given the much-needed opportunity to re-establish my clinical confidence. After this I became involved in education and returned to health visiting and primary health care research and development. It was in the field of research that my interest in the use of theory developed. In teaching research I became concerned with the lack of a theoretical base for much of the nursing and midwifery research I read and the lack of understanding among many nurses and midwives of the need for a theoretical framework for their research. Many people are still involved in constructing data-collection tools and collecting data without thinking about how that data relates to available knowledge and theory, the wider body of research and theory development which reduces the usefulness of their research. On the other hand, there is a growing body of qualitative research which does not start with a theoretical framework but aims to understand what is going on and develop theory from the data collected. There are, then, two traditions in research. The first uses available theory and knowledge to construct a theoretical framework which is investigated through research (deductive theorising) and the second starts with the (socalled) blank sheet - data is collected in relation to a phenomenon and theory is developed from that data (inductive theorising).

I therefore came to the task of thinking about theory in midwifery with a fairly open mind. I came to much of the literature on nursing models for the first time and found that in reading much of it I felt disquiet about four things. Firstly, my feelings of disquiet related to the lack of the presence of the individual nurse in the models. There was no reference to the personality of the nurse, the values, attitudes or needs of the nurse. My experience of midwifery and reading of midwifery literature made me feel that the personality of the midwife was vital and that there was a need in midwifery care for the midwife to understand her or himself. It was only when I re-read Carper (1992, originally published in 1978) that I began to find an answer to my disquiet in her discussion of personal knowledge and knowing the self. It was extremely reassuring to find that others were concerned with the person of the nurse. A paper by Taylor (1992) which discusses the need to re-identify nurses as human beings reinforced my feeling that awareness of the individual characteristics (the self) of the midwife should be discussed in a book on the use of models in midwifery.

My second feeling of disquiet about nursing models was the distance of many of the models from practice. Many of the most familiar nursing models are largely deductive theories which have been constructed from pre-existing models and theory, usually from 
disciplines outside nursing. These models present broad descriptions of ways of thinking about practice. They present broad descriptions of the relationship between concepts, and the research on testing the relationships between the concepts in the theories and models is patchy. These models and theories often seem to be very distant from everyday practice, and people seem to have to make a great deal of effort to apply these theories to practice. Reading Agyris and Schön (1974) helped me to see that what I was more concerned about were people's theories-inuse, the theories they use in their everyday practice or practice theory. It was this type of theory that had been troubling me during the project at Queen Charlotte's: how did the midwives actually undertake their practice? It was not sufficient to have descriptions of their theories-inaction, which espoused individualised care, when individualised care was self-evidently not being provided. Organisational theory and an understanding of the constraints on practice imposed by the organisation helped to explain the care provided, but this did not provide the full explanation. This could only be provided by an understanding of the theories-in-use which the midwives used to provide the care that was possible in that situation but which was not too dissonant with their own personal values about midwifery practice.

A third concern that I had about nursing models was the reaction that midwives would have to a book on the use of models in midwifery. One of my first thoughts about midwives and models was that midwives would have an antipathy to anything which was about the use of models. They would think that this is a book about the use of nursing models in midwifery, and to begin with, that is what I thought this book might be about. However, reading the literature showed me that there was a great deal more to the work of theory development in midwifery than the application of nursing models, important though that may be. One disappointment $I$ have is that $I$ have not been able to include some of the work that is currently progressing in Britain on theory development but which is as yet unpublished. I placed letters in a number of professional journals but these produced little response. Perhaps this publication will stimulate those who have undertaken work on theory development to publish their findings.

Finally, during the writing of this book I was fortunate to hear two eminent American nurse theorists talking at a conference, but what I heard filled me with fear, and it is this fear which is my last concern about the use of models in practice. Some nurse theorists seem to have gone so far down the path of existentialism that the everyday needs of the patient or childbearing woman seem to be lost in an understanding of the deeper self and needs of the individual, aspects of themselves 
which they themselves may not understand. The language used by some nurse theorists is extremely complicated and their meaning is often unclear. Language and the promotion of extreme philosophical positions creates a further barrier to our interest in thinking about how we practise. Much of the writing on models contributes to these barriers.

It has, however, been exciting to find that so much work has been undertaken on the development of theory in midwifery and nursemidwifery practice contrary to much popular opinion on the subject. It has been particularly interesting to discover the work that has been done on theory testing, a vital part of the development of understanding of the relationship between midwifery actions and outcomes for the childbearing woman.

I hope that this book helps to reduce the barriers to thinking about theory and midwifery practice and helps you in your journey of understanding about how you think about midwifery and the care of the childbearing woman and her family. I have tried to explain how I have come this far on the journey. I now look forward to seeing how theory building in midwifery progresses in the future.

ROSAMUND BRYAR

Swansea 
A whole host of people have helped in various ways with the writing of this book. My mother has borne the brunt of the effort and time that I have expended on this work and I thank her for her continued support, encouragement, patience and advice on use of the English language. Quentin, Siobhàn and Saoirse, my brother, his wife and young daughter have all provided me with much-needed support. Special thanks must go to Graham Evans of the University of Wales Swansea for advice and encouragement throughout the project. Four people whom I would also like to thank, Halle McCrae, Donna Mead, Ann Thomson and Edwin van Teijlingen, have given me particular help by reading and commenting on chapters. I would like to thank Halle McCrae for her encouragement. Donna Mead provided useful references, and discussion with her about Chapter 2 helped to clarify my thoughts. Ann Thomson provided, as usual, many challenging and helpful comments. Edwin van Teijlingen, in addition to his useful comments, has provided me with invaluable references and undertook the calculation in Chapter 3. A number of other people have provided particular help. I would like to thank Pam Hughes and Sandy Kirkman for early discussions; Joanna Brown typed some chapters and I would like to thank her for this and for her encouraging telephone calls; Chris Ruby for her encouragement and comments on one section; Hugh Price, Lecturer in Philosophy, for locating Socrates; Florence Telfer and Dorothy Carter for permission to use their unpublished work; Sally Pairman, Otago Polytechnic, New Zealand for permission to quote from the New Zealand handbook; Jon Meah and Chris Weeks, Babbage Designs, for the original art work on the diagrams and for their encouragement; Bill Bytheway for his general advice and Jo Alexander for getting me into this in the first place. I would like to thank my former colleagues at Teamcare Valleys (who could never quite understand my interest in midwifery) for their support and help in developing my thinking and my new colleagues in the midwifery teaching department of the Department of Nursing and Midwifery for their tolerance and helpful discussions about models. Many people have also contributed indirectly to the production of this book. These include the students on the Diploma in Midwifery in Cardiff, midwifery lecturers in the Mid Glamorgan College of Nursing and Midwifery and the Amman Valley Midwives, all of whom helped to keep me in contact with midwifery developments. The roots of this book lie in a project that was undertaken at Queen Charlotte's Maternity Hospital (1979-82) and I would like to thank all the midwives, students and other staff who were 
involved in that project and contributed so much to it. In particular I would like to thank Margaret Adams, Grace Strong and Mrs E. Ward who initiated the project. Kerry Lawrence, then Commissioning Editor at Macmillan, persuaded me to write this book - I hope it answers some of her questions about models and theory building. Finally, I would like to thank Barbara Green, Director of the Department of Nursing and Midwifery, University of Wales Swansea, for giving me the time to write.

A number of figures and tables have been reproduced in this book with the kind permission of the following:

Figure 2.2 with the permission of Macmillan Press Ltd.

Figure 3.1 with the permission of Heinemann Educational Books Ltd and Professor David Silverman.

Figure 6.3 with the permission of the American Journal of Nursing Company, 1988. Reprinted from American Journal of Nursing, Sept./Oct. 1988, Vol. 37, no. 5.

Figure 6.8 with the permission of Cambridge University Press.

Table 5.1 with the permission of Mark Allen Publishing Ltd.

Table 7.1 with the permission of Churchill Livingstone. 